\title{
Testing and modeling of a traditional timber mortise and tenon joint
}

\author{
Artur O. Feio • Paulo B. Lourenço • \\ José S. Machado
}

Received: 21 May 2012/Accepted: 15 March 2013/Published online: 26 March 2013

(C) RILEM 2013

\begin{abstract}
The structural safety and behaviour of traditional timber structures depends significantly on the performance of their connections. The behaviour of a traditional mortise and tenon timber joint is addressed using physical testing of full-scale specimens. New chestnut wood and old chestnut wood obtained from structural elements belonging to ancient buildings is used. In addition, the performance of different semi and non-destructive techniques for assessing global strength is also evaluated. For this purpose, ultrasonic testing, micro-drilling and surface penetration are considered, and the possibility of their application is discussed based on the application of simple linear regression models. Finally, nonlinear finite element analysis is used to better understand the behaviour observed in the full-scale experiments, in terms of failure mode and ultimate load. The results show that the ultrasonic pulse velocity through the
\end{abstract}

\section{A. O. Feio $(\bowtie)$}

Faculty of Architecture, University Lusíada, Largo Tinoco de Sousa, 4760-108 Vila Nova de Famalicão, Portugal e-mail: artur.feio@fam.ulusiada.pt; arturfeio@gmail.com

\section{P. B. Lourenço}

Department of Civil Engineering, ISISE, University of Minho, Azurém, 4800-058 Guimarães, Portugal e-mail: pbl@civil.uminho.pt

\section{J. S. Machado}

Timber Structures Division, National Laboratory for Civil Engineering, Lisbon, Portugal

e-mail: saporiti@lnec.pt joint provides a reasonable estimate for the effectiveness of the assembly between the rafter and brace and novel linear regressions are proposed. The failure mechanism and load-displacement diagrams observed in the experiments are well captured by the proposed non-linear finite element analysis, and the parameters that affect mostly the ultimate load of the timber joint are the compressive strength of wood perpendicular to the grain and the normal stiffness of the interface elements representing the contact between rafter and brace.

Keywords Ancient timber structures - Chestnut wood - Semi and Non-destructive methods - Pilodyn · Resistograph · Ultrasonic testing · Experimental testing · Finite element analysis · Nonlinear mechanics

\section{Introduction}

In the past, timber structural design was dominated by carpenter know-how, resulting from tradition and empirical knowledge. Even if it was evident that some members were subjected to tension and others to compression stresses, the observation of old timber structures indicates often a complex structural understanding. Deterioration of timber trusses led often to some sort of anarchy in ancient structures due to continuous changes and repair works, mostly with 
additional stiffening or propping, resulting in heterogeneity of the members, a multiplicity of connections and diversity of supports. With respect to traditional wood-wood joints, rules-of-thumb dominated the technology and the present knowledge is still rather limited [29, 30, 22]. However, there has been a growing interest in this field [23, 26, 10, 13].

In the present research program, a mortise and tenon joint, see Fig. 1, was selected because it is one of the most commonly used in ancient timber structures and a typical example of an interlocking joint. Mortise and tenon joints connect two or more linear components, forming usually an " $\mathrm{L}$ " or " $\mathrm{T}$ " type configuration. The key problem found in these joints is the possible premature failure induced in the structure caused by large displacements in the joint $[24,20]$.

The bearing capacity of mortise and tenon joints is a function of the angle of the connection, and length of the toe and mortise depth [1, 14, 17]. The lack of knowledge about this particular joint is determinant in the assessment of the load carrying capacity of existing wooden structures [9, 31, 4, 5]. Here, the objective are to quantify the strength capacity of the joint by physical testing of full-scale specimens, to validate the possible usage of semi and non-destructive testing techniques to predict the joint properties and the joint effectiveness and to validate the adequacy of an anisotropic failure criterion to represent the behaviour of the joint by the comparison between experimental and numerical results.

The adopted semi-destructive methods (SDT) and non-destructive methods (NDT) for the joints are the Pilodyn, Resistograph and ultrasonic tests, respectively, which are standard techniques for wood testing
$[2,15]$. For testing the joint effectiveness the ultrasonic test was used [27].

For the purpose of numerical analysis wood is often considered as an orthotropic or transverse isotropic material with different properties in three mutually orthogonal directions, axial, radial and tangential $[32,33]$.

Here, the finite element method is adopted to simulate the structural behaviour and obtain a better understanding of the failure process observed in experimental tests. Calculations are performed using a plane stress continuum model and the failure criterion is based on multi-surface plasticity, comprising an anisotropic Rankine yield criterion for tension, combined with an anisotropic Hill criterion for compression. The full Newton-Raphson method, with stiffness matrix update in each iteration is used in the analyses carried out in this work.

In the case of timber joints, two-dimensional approaches, e.g [3], and three-dimensional approaches, e.g. $[12,21]$, have been used in the past. Therefore, calculations are performed here using a plane stress continuum model combined with different thicknesses and possible slip provided by the addition of interface elements. Given the adoption of a 2D model some parameters could not be taken fully into account, namely geometric imperfections (joints and members), the contact friction between tenon and mortise and nonuniform stress distribution inside the joint.

The plane stress model can capture different strengths and softening/hardening characteristics in orthogonal directions $[8,28]$. Using the finite element model, the influence of compression perpendicular to the grain and elastic stiffness on the response is addressed in detail.
Fig. 1 Details of a typical tenon and mortise joint, with the geometry adopted in the testing program (dimensions in $\mathrm{mm}$ )
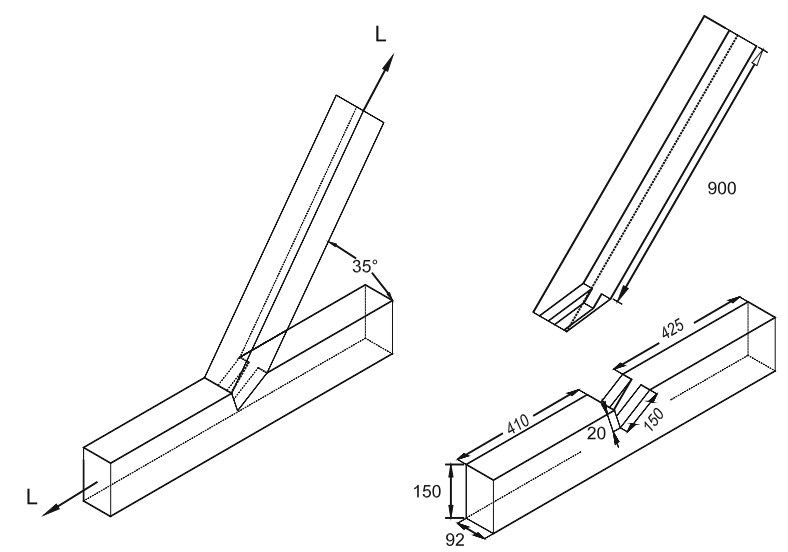

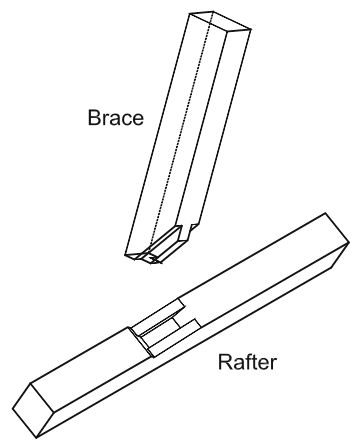




\section{Description of test specimens}

Chestnut wood (Castanea sativa Mill.) is usually present in historical Portuguese buildings and all the wood used in the test specimens came from the North of Portugal. In order to assess the influence of service time in the response, two groups were considered: New chestnut wood (NCW), obtained from recently sawn timber, and old chestnut wood (OCW), obtained from structural elements belonging to ancient buildings (date and precise origin unknown) with unknown load history. The old logs were obtained from rehabilitation works and were provided by a specialist contractor claiming that the wood has been in service for over 100 years. All specimens were prepared by the same carpenter, under similar moisture conditions and aiming at including the fewest possible defects. An electronic device registered the air temperature and relative humidity during the tests. The average values of temperature and relative humidity were $24 \pm 2{ }^{\circ} \mathrm{C}$ and $52 \pm 12 \%$, respectively. The time elapsed between the tests and withdrawal of the specimens from the climatic chamber (less than $24 \mathrm{~h}$ ) did not affect the conditioning of the specimens.

Each specimen consists of two timber elements, with a cross section of $92 \times 150 \mathrm{~mm}$, connected by a mortise and tenon joint without any pegs, see Fig. 1. Because of their frequency in the preliminary roofs survey undertaken, the angle between the elements is $65^{\circ}$. Density tests were carried out in samples removed from the specimens' ends. Similar average values were found for NCW and OCW group, with an average of $593.6 \mathrm{~kg} / \mathrm{m}^{3}$ for NCW and $568.8 \mathrm{~kg} / \mathrm{m}^{3}$ for OCW (4\% difference), indicating that the sample is relatively homogenous on average. The coefficient of variation in each sample is high: $25 \%(\mathrm{NCW})$ and $31 \%$ (OCW), see [11] for details.

\section{Experimental program}

The specimens were tested under compression in order to assess local compressive failure and slipping of the joint, see Fig. 2. One hydraulic jack was used to apply a compression force aligned with the rafter, with a programmed loading cycle. The system included a support plate with stiffeners, able to rotate and to ensure verticality of the brace. The support plate included a toe so that the rafter did not slide. The brace was kept in the original vertical alignment with a horizontal bar, connected to a load cell. The jack had a maximum loading capacity of $300 \mathrm{kN}$ and a maximum stroke of $200 \mathrm{~mm}$.

The displacements were measured using linear variable differential transducers (LVDTs), with an accuracy of $\pm 0.025 \mathrm{~mm}$ and continuously recorded until failure. The vertical and horizontal displacements in the specimens were measured by two pairs of LVDTs placed on opposite faces of the specimens.

The loading procedure consisted of the application of two monotonic load stages, EN 26891 [6]: firstly, the load was applied up to $50 \%$ of the estimated maximum load and was maintained for $30 \mathrm{~s}$. The load was then reduced to $10 \%$ of the estimated maximum load and maintained for another $30 \mathrm{~s}$. This procedure was repeated once again and, thereafter, the load was increased until ultimate load or until a maximum slip of $15 \mathrm{~mm}$ between the two timber elements was reached.

A constant rate of loading corresponding to about $20 \%$ of the estimate maximum load per minute was used, leading to a total testing time of about 9-12 min. Each load-displacement (vertical displacement of the brace) curve was reduced to a force-displacement plot. The ultimate load of the joint $\left(F_{\text {ult, joint }}\right)$ was defined as the conventional value corresponding to a strain equal to a $2 \%$ offset in the usual terminology (Nbr7190, 1997), as shown in Fig. 3.

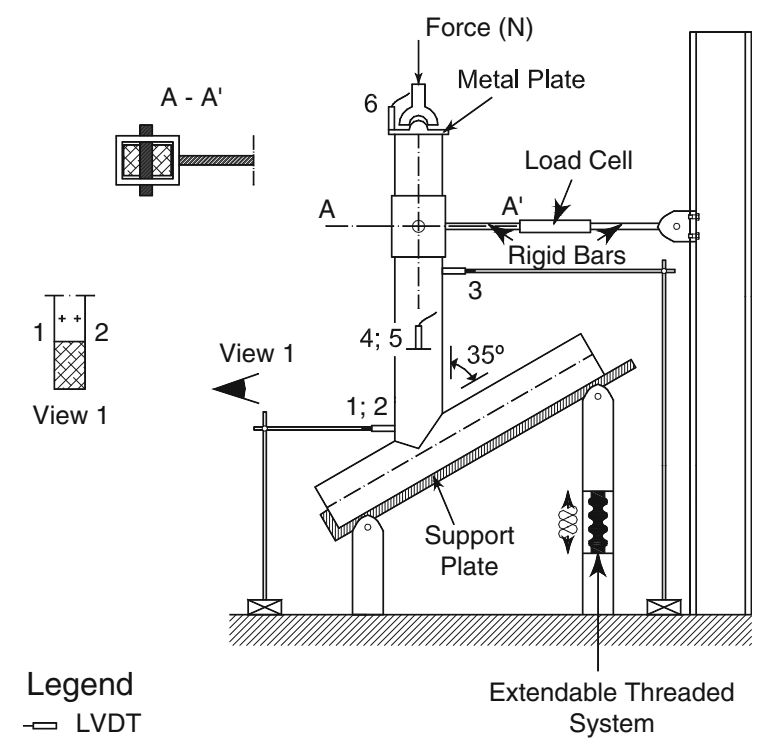

Fig. 2 Aspects of the test set-up and location of LVDTs 


\subsection{Ultimate force and failure patterns}

Table 1 shows the results of the tests in terms of ultimate force. The scatter found is moderate, with the ultimate force ranging between $121.6 \mathrm{kN}$ up and $161.5 \mathrm{kN}$. Even if the number of specimens is rather low, the average force in terms of groups NCW and OCW exhibits only a marginal difference. Specimen J_7 was discarded in this table because the ultimate load found $(98.5 \mathrm{kN})$ was very low and controlled by a local defect: a longitudinal crack in the rafter.

The main characteristic of the adopted joint is that the direction of the grain of the two assembled pieces it is not coincident, forming an acute angle. The rafter was loaded in the direction parallel to the grain, whereas the brace was loaded at an oblique angle inducing large stresses perpendicular to the grain. Due to the anisotropic behaviour of wood, wood stressed parallel to the grain presents the highest values of strength. Therefore, the rafter, stressed in compression parallel to the grain, easily penetrates the brace. The compressive damage in the brace occurred either localized at the toe or distributed along the full contact length. Often, out-of-plane bulging of the rafter under the contact length was observed. In some cases, compressive damage was accompanied with shear failure in the rafter in front of the toe. Figure 4 illustrates the typical damages observed at ultimate load.

The specimens were produced avoiding the presence of large defects although accepting small defects.

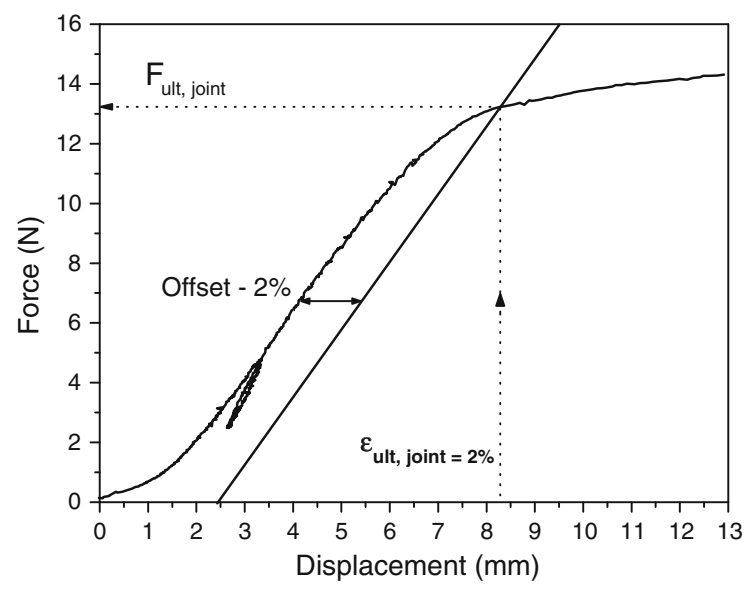

Fig. 3 Definition of the ultimate load from the force-displacement diagram
Table 1 Test results: ultimate force

\begin{tabular}{lllll}
\hline & Ultimate Force $(\mathrm{kN})$ & Average & Std. Dev. & Group \\
\hline J_1 & 121.6 & 145.4 & 18.9 & NCW \\
J_2 & 161.5 & & & \\
J_3 & 159.7 & & & \\
J_4 & 138.9 & & & \\
J_5 & 126.4 & 145.5 & 16.7 & OCW \\
J_6 & 157.1 & & & \\
J_8 & 153.0 & & & \\
\hline
\end{tabular}

During the tests it was observed that the longitudinal and radial cracks of moderate width (1-2 $\mathrm{mm}$ ) in the rafter had a minor influence in the ultimate force and in the global behaviour of the joints. The longitudinal pre-existing cracks tend to close and the radial preexisting cracks tend to open, being this behaviour more noticeable when the cracks are close to the joint. On the other hand, the cracks present in the brace, namely the longitudinal ones, show a tendency to propagate and to open during the tests.

\subsection{Load-displacement diagrams}

The envelope of all tests in terms of load-displacement diagrams, given by the vertical force versus vertical/absolute displacement of the brace, is given in Fig. 5. In a first phase, the diagrams exhibit a nonlinear response, which is due to the adjustment of the tenon and the mortise. In a second phase, within working stress levels, the response exhibits an approximately linear branch up to the ultimate force, which occurred at an average displacement of $7.5 \mathrm{~mm}$. It is noted that unloading-reloading cycles within working stress levels provide a constant stiffness, which is higher than the loading stiffness, see Fig. 3. The justification of this behavior is attributed to the nonlinear behavior of the interface between rafter and brace, which exhibits a closure phenomenon. Finally, after the ultimate force the displacement increases rapidly with a much lower stiffness, due essentially to the compressive failure of the wood in the rafter around the joint.

Figure 6 shows the relation between the vertical load and the horizontal load (reaction load measured in the horizontal load cell). It can be observed that the horizontal reaction varies between 0 and $3.5 \%$ of the 

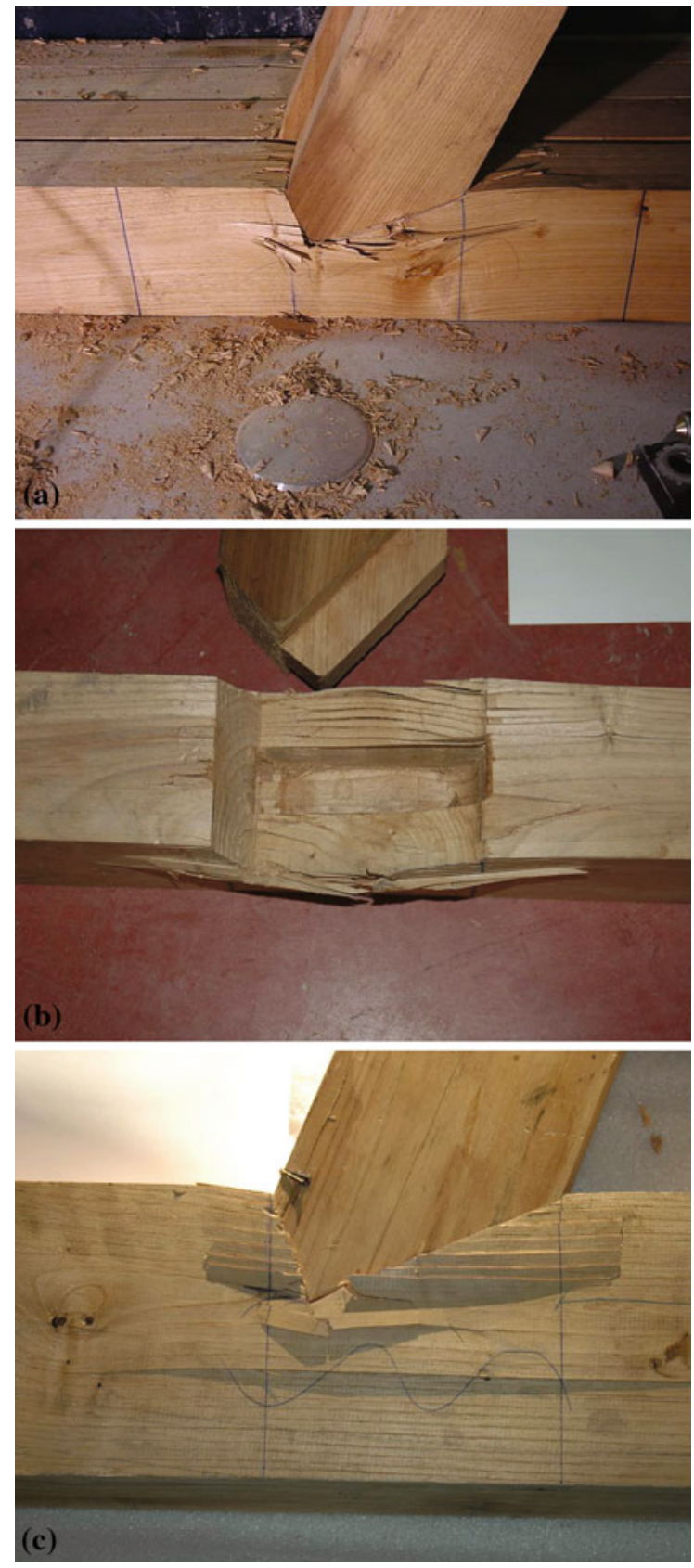

Fig. 4 Typical experimental failure patterns observed: a joint collapsed in compression, with uniform distribution of damage, b joint collapsed in compression, with out-of-plane bulging, and c combined failure in compression and shear parallel to the grain at the toe

vertical load. Such low values indicate that the horizontal effects in the testing set-up can be neglected for practical purposes.

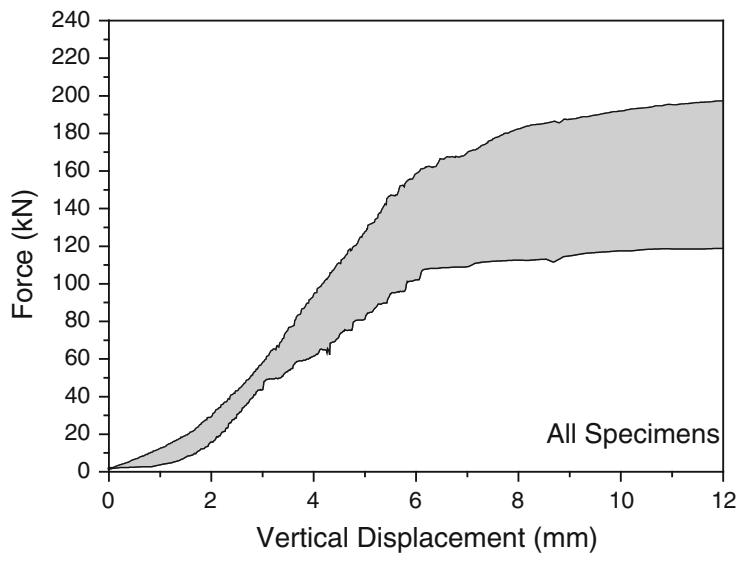

Fig. 5 Envelope of load-absolute displacement of the brace diagrams

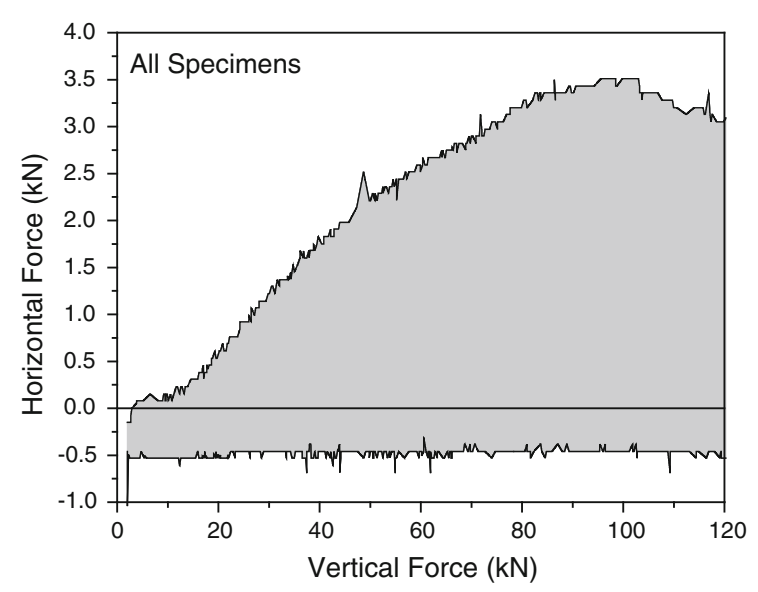

Fig. 6 Envelope of the relation between horizontal reaction and vertical force

\subsection{Correlations between density, ultimate load and stiffness}

Higher wood density means usually higher stiffness and strength. Figure 7 shows the relations between density and ultimate load, in case of the brace and of the rafter, as the structural response is controlled by the rafter. It is clear that no correlation can be found. A possible reason for this result is that the structural response is controlled by the local characteristics of wood and density was measured at the specimens' ends.

\section{Semi and non-destructive testing}

In order to investigate possible correlations and to validate the use of semi-destructive and non-destructive 


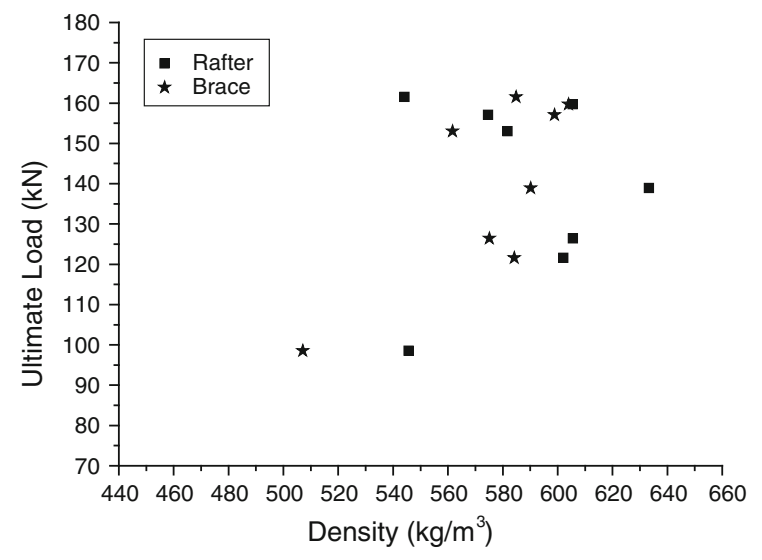

Fig. 7 Ultimate load versus density for all tests

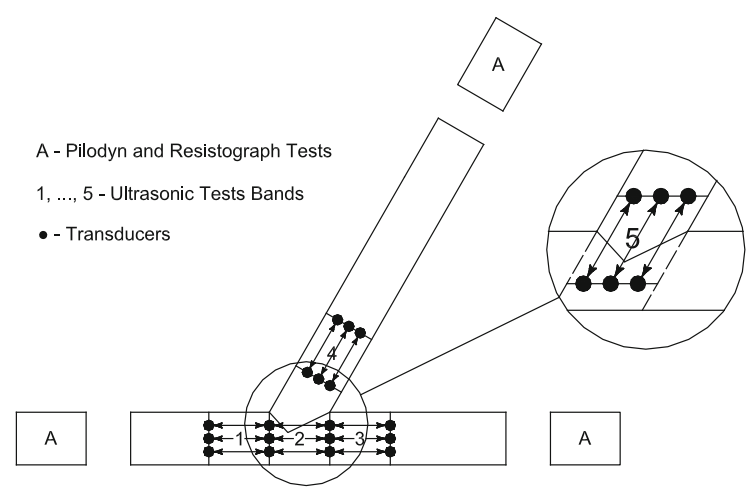

Fig. 8 Location of semi-destructive and non-destructive tests

techniques for the evaluation of the joint the Resistograph, the Pilodyn and ultrasonic tests have been used, see Fig. 8. Average values were considered in all measurements, using two readings per specimen, per side, as described below. A third reading was added only if the two first readings differed significantly. Pilodyn and Resistograph have been carried out in samples removed from the elements ends, in order not to affect the strength of the joint, whereas the ultrasonic tests were carried out at the joint location.

\subsection{Resistograph and Pilodyn test procedure}

Drilling and impact penetration was made on planes TL and LR, which, in real cases, represents the accessible faces of timber elements. Micro-drilling measurements were made using the Resistograph $3450-\mathrm{S}$ and a $3 \mathrm{~mm}$ diameter drill bit. The resistographic measure (RM) was calculated from the
Table 2 Average results of the Resistograph Tests (values in bits/mm)

\begin{tabular}{llll}
\hline & Brace & Rafter & Group \\
\hline J_1 & 449.5 & 464.1 & NCW \\
J_2 & 367.7 & 471.7 & \\
J_3 & 365.0 & 424.5 & \\
J_4 & 463.6 & 412.3 & \\
J_5 & 391.7 & 474.3 & OCW \\
J_6 & 332.0 & 495.2 & \\
J_7 & 396.6 & 390.5 & \\
J_8 & 323.1 & 432.0 & \\
\hline
\end{tabular}

Table 3 Average results of the Pilodyn tests (values in $\mathrm{mm}$ )

\begin{tabular}{llll}
\hline & Brace & Rafter & Group \\
\hline J_1 & 8.0 & 8.0 & NCW \\
J_2 & 7.8 & 8.8 & \\
J_3 & 8.0 & 7.3 & \\
J_4 & 8.0 & 7.3 & OCW \\
J_5 & 8.0 & 8.2 & \\
J_6 & 8.0 & 7.3 & \\
J_7 & 9.0 & 8.8 & \\
J_8 & 8.7 & 8.2 & \\
\hline
\end{tabular}

diagram obtained with the Resistograph, see [19], as the ratio between the integral of the area of the diagram and the length $l$ of the drilled perforation. The average results are presented in Table 2 . The Pilodyn $6 \mathrm{~J}$ can measure the penetration of a metallic needle with $2.5 \mathrm{~mm}$ of diameter, which is inversely proportional to the density of the wood, evaluating the surface hardness or resistance to superficial penetration. The average results are presented in Table 3.

\subsection{Ultrasonic test procedure}

A Pundit/Plus device (ultrasound generator) and a pair of cylinder-shaped transducers $(150 \mathrm{kHz})$ were used for ultrasonic testing. In all tests, performed after cutting the joints but before load testing, coupling between the transducers and the specimens was assured by a conventional hair gel, and a constant coupling pressure was applied on top of the transducers by means of a rubber spring. Given the dimensions of the wood elements and the diameter of the transducers used $(\phi=25 \mathrm{~mm})$, a reference testing 
Table 4 Results of the ultrasonic tests (average and standard deviation values in $\mathrm{m} / \mathrm{s}$ )

\begin{tabular}{lrrr}
\hline & Brace & \multicolumn{1}{c}{ Joint } & Rafter \\
\hline NCW & & & \\
Average & 4484.0 & 3940.8 & 4776.0 \\
SD & 182.2 & 34.0 & 131.1 \\
OCW & & & \\
Average & 4559.4 & 3826.3 & 4613.5 \\
SD & 153.7 & 49.8 & 97.2 \\
\hline
\end{tabular}

mesh was defined on the central mid-third of each element, as shown in Fig. 8. Five distinct locations were defined, corresponding to three distinct zones of testing: (a) three locations in the brace, (b) one location in the rafter, and (c) one location in the joint.

The tests in the brace and rafter aimed at characterizing the mechanical properties of the elements in the zones nearby the joint. The test across the joint tried to evaluate in a qualitative way the effectiveness of the assembly between the two elements. A throughtransmission indirect method (both transducers placed on the same surface) was adopted measuring the wave propagation velocity parallel to the grain in each element and joint. The average and the standard deviation results for the ultrasonic pulse velocity, for each considered group, are presented in Table 4.

\subsection{Results and correlations with semi and non- destructive tests}

Figure 9 shows the correlations between the ultimate load and the measurements made in the rafter using the Pilodyn and Resistograph techniques. Because the measurements have been made in specimens' ends and not at the joint location, no correlation could be found. This conclusion holds if the rafter and brace are considered together [11]. Similar results were found for the mechanical properties of chestnut perpendicular to the grain in Lourenço et al. [19].

Figure 10a illustrates the relation between the ultimate load and the ultrasonic pulse velocity. The results show that ultrasonic pulse velocity could be a good indicator for the prediction of the ultimate load. Here, it is noted that the results using local measurements only in the rafter, or rafter and brace together provide better correlations than measurements across the joint. In the latter, also the stiffness of the joint is
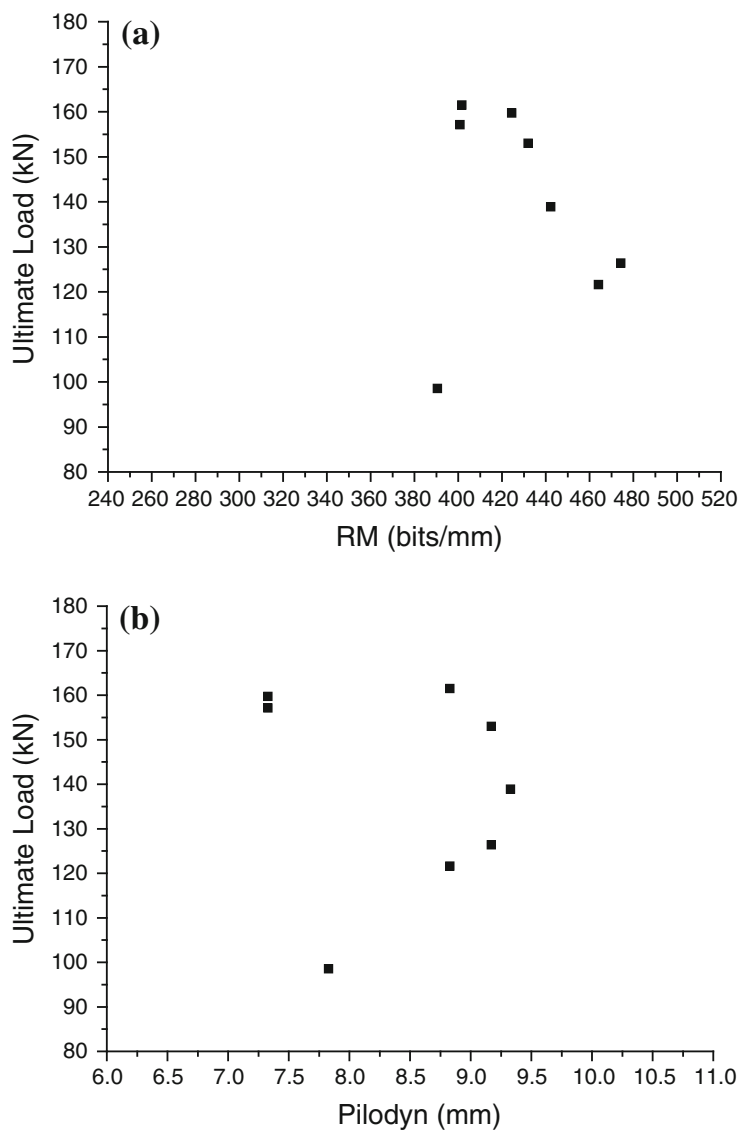

Fig. 9 Ultimate load versus a resistographic measure and b Pylodyn. Results for rafter only

taken into account, meaning that the ultrasonic pulse velocity is much lower. The joint stiffness is also a relevant parameter for the estimation of deformations and strength of existing timber structures. Figure $10 \mathrm{~b}$ illustrates the correlation between joint stiffness $k_{\text {joint }}$ and the ultrasonic pulse velocity across the joint. A clear linear correlation was found, indicating that it seems possible to estimate joint stiffness from ultrasonic testing.

\section{Numerical simulation}

In order to further discuss the experimental results, a finite element simulation of the tests has been carried out and continuum quadratic elements (8-noded) were used to represent the wood and to represent the line interface between rafter and brace quadratic elements (6-noded) were used. The integration schemes used 

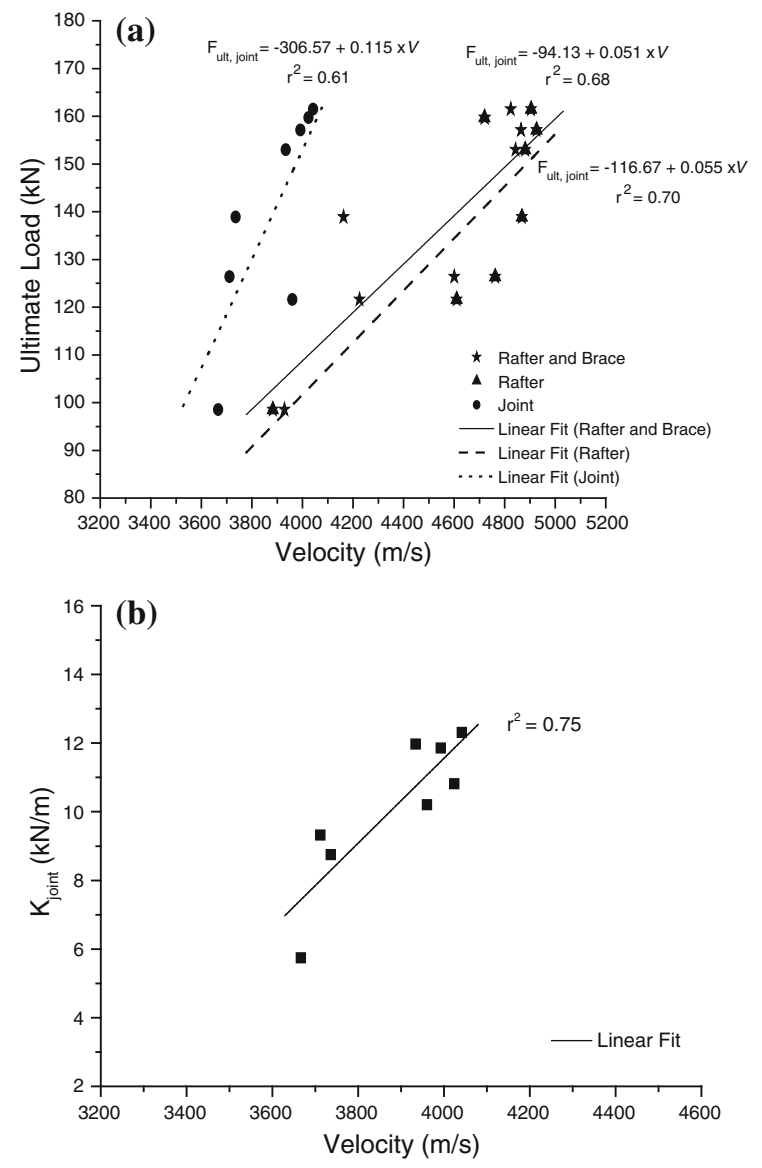

Fig. 10 Ultrasonic pulse velocity method for all tests: a relation between the ultimate load and the ultrasonic pulse velocity, and b joint stiffness versus ultrasonic pulse velocity

are $2 \times 2$ Gauss integration points for the continuum elements and 3 Lobatto integration points for the interface elements. The simulations have been carried out using a globally convergent solution process, combining a Newton-Raphson method with arclength and line search.

The adopted failure criterion for wood consists of an extension of conventional formulations for isotropic quasi-brittle materials to describe orthotropic behaviour. It is based on multi-surface plasticity, including a Hill yield criterion for compression and a Rankine yield criterion for tension, and having different strengths in the directions parallel and perpendicular to the grain, see [18] for details.

In the present case, the tensile part of the yield criterion was ignored due to the irrelevant contribution of the tensile strength in the global behaviour of the joint. This means that the yield surface reduces to the
Table 5 Adopted elastic and inelastic material properties

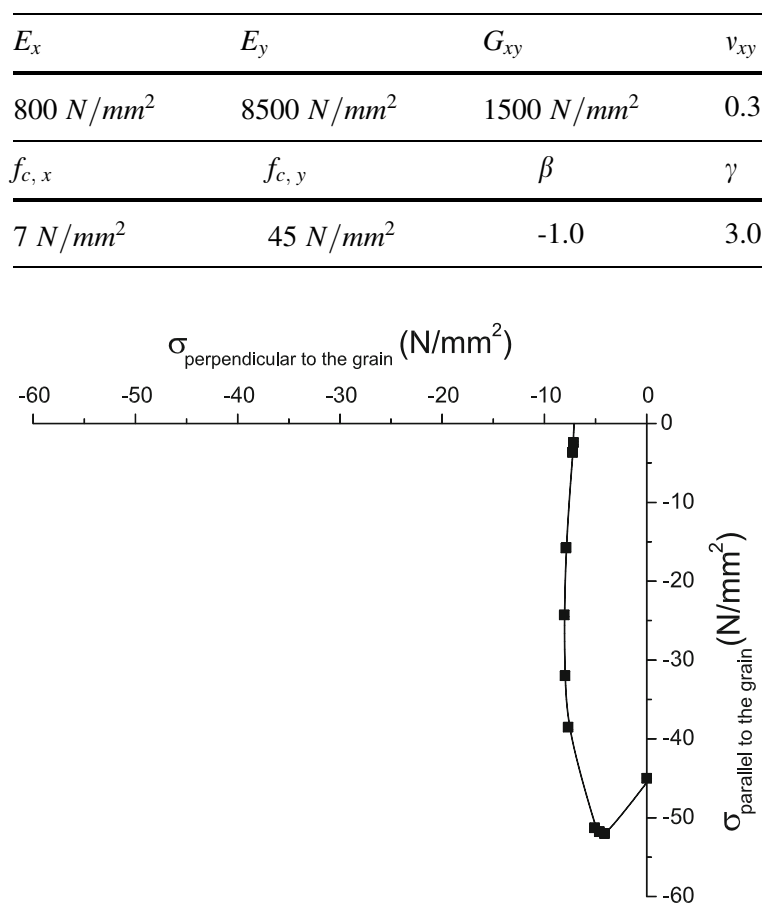

Fig. 11 Shape of the proposed yield criterion for chestnut wood. Material parameters: $f_{\mathrm{c}, x}=7.0 \mathrm{~N} / \mathrm{mm}^{2} ; f_{\mathrm{c}, y}=45 \mathrm{~N} /$ $\mathrm{mm}^{2} ; \beta=-1.0 ; \gamma=3.0$

standard Hill criterion in compression. The adopted elastic and inelastic materials properties are detailed in Table 5 and have been obtained from a testing program aiming at characterizing chestnut, see [19, $11]$.

Figure 11 illustrates the shape of the adopted yield criterion in the compression-compression regime, which features an extreme degree of anisotropy with a ratio $f_{c, x} / f_{c, y}=0.156$.

\subsection{Numerical versus experimental results}

A structured mesh is used for the rafter and the brace, whereas an irregular transition mesh is used in the vicinity of the connection between rafter and brace. Interface elements are also used between the rafter and the brace. The thickness ranges from 62 to $93 \mathrm{~mm}$, as shown in Fig. 12a. This aims at representing the thickness of the mortise.

The comparison between numerical and experimental load-displacement diagrams is given in Fig. 12b. A preliminary analysis with an infinite stiffness of the interface, assuming a fully rigid 


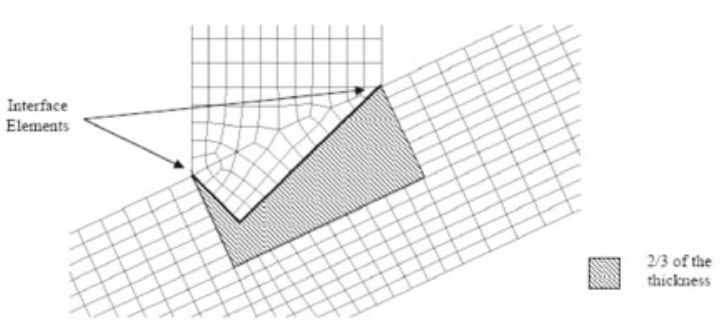

(a)

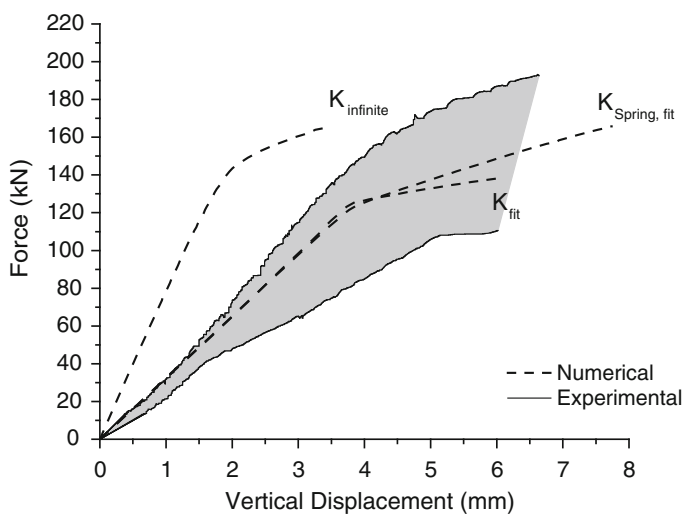

(b)

Fig. 12 a localization of the interface elements, and b comparison between numerical and experimental load-displacement diagrams

connection, indicated that such an assumption provided far too stiff results. Therefore, the stiffness of the interface elements was obtained by inverse fitting. Given this procedure and taking into account the possibility of using this model towards other joint geometries and/or loadings, the model present a great sensitivity to the stiffness of the interface elements. Thus, a first conclusion is that the stiffness of the interface elements has considerable influence on the yield strength of timber joints.

In Fig. 12b, three distinct situations are presented:

- a numerical simulation with infinite stiffness of the interface elements in the normal direction, $k_{\mathrm{n}}$, and shear direction, $k_{\mathrm{s}}\left(k_{\text {infinite }}=k_{\mathrm{n}}=k_{\mathrm{s}}=10^{9} \mathrm{~N} / \mathrm{mm}^{3}\right)$;

- a numerical simulation with an adjusted stiffness of the interface elements obtained by inverse fitting of the experimental results $\left(k_{\mathrm{fit}}\right)$, assuming that the shear and normal stiffness are related via the Poisson's coefficient $v$ by $k_{\mathrm{s}}=k_{\mathrm{n}} / 2 /(1+v)$ : $k_{\mathrm{n}}=6000 \mathrm{~N} / \mathrm{mm}^{3}$ and $k_{\mathrm{s}}=2308 \mathrm{~N} / \mathrm{mm}^{3}$;

- a numerical simulation with a spring $\left(k_{\text {spring }}=\right.$ $10^{6} \mathrm{~N} / \mathrm{m}$ ) located in the brace to simulate the

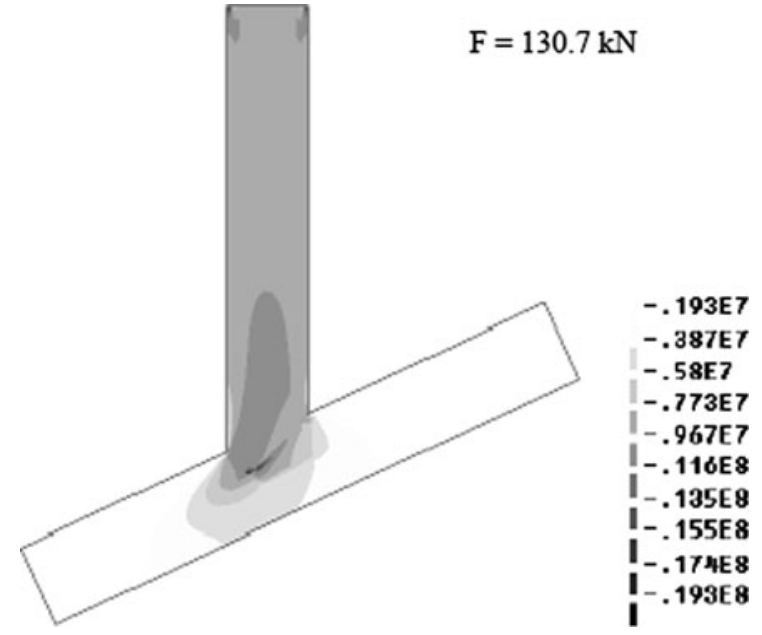

Fig. 13 Minimum principal stresses (values in $\mathrm{N} / \mathrm{m}^{2}$ ) at ultimate load

reaction cell used in the experimental sets. The stiffness of the spring was again obtained by inverse fitting of the experimental results, keeping the adjusted stiffness of the interface elements.

For the purpose of numerical analysis, the loaddisplacement diagrams were corrected with an offset that eliminates the upward curve related to the nonlinear behaviour of the joint previous to full contact (joint closure). The numerical results, in terms of force-displacement diagrams, with the adjusted stiffness for the interface elements, provide very good agreement with the experimental results both in the linear and nonlinear parts. The influence of the experimental horizontal restraint, simulated by a linear spring, is only marginal.

A more relevant conclusion is that the usage of infinite stiffness for the interface (rigid joint) results in an increase of the slope of the first part of the response, from 30 to $80 \mathrm{kN} / \mathrm{mm}(+266.7 \%)$. The ultimate force of the joint, given by an offset of the linear stretch by $2 \%$ in terms of strain values, also changes from 130 to $152 \mathrm{kN}(+17 \%)$, once the joint becomes fully rigid.

Figure 13 shows the contour of minimum principal stresses at ultimate load. It is possible to observe a concentration of stresses in a narrower band with peak stresses at the joint (zone where the interface elements were placed), upon increasing loading. As observed in the experiments, failure is governed by wood crushing, being the compressive strength of the wood, in the direction perpendicular to the joint, exhausted at failure. 


\subsection{Sensitivity study}

A strong benefit of using numerical simulations is that parametric studies can be easily carried out and the sensitivity of the response to the material parameters can be easily evaluated. This allows a better understanding of the structural response. However, it is important to understand the limitations of the model given the adoption of a 2D model, as referred some parameters could not be taken fully into account, and the introduction of interface elements referred. In this perspective a future 3D model can bring some additional accuracy to the results now obtained.

The influence of the key parameters of the model in the response will be analyzed separately. The values $k_{\mathrm{n}}$ (normal stiffness of the interface), $k_{\mathrm{s}}$ (tangent stiffness of the interface), $E_{x}$ and $E_{y}$ (Young's moduli in the directions parallel and perpendicular to the grain, respectively) are assumed to be less well known and variations of 50 and $100 \%$ are made. $f_{x}$ and $f_{y}$ (compressive strengths in the directions parallel and perpendicular to the grain, respectively) are assumed to be well known and variations of +25 and $-25 \%$ are made, corresponding to 0.75 and 1.25 times the initial value.

\subsubsection{Normal and tangential stiffness of the interface}

Figure $14 \mathrm{a}$ shows a comparison between the results of the variation of the normal joint stiffness: with a reduction of $50 \%$ in $k_{\mathrm{n}}$, the ultimate force of the joint, given by an offset of the linear stretch by $2 \%$, decreases from 127.2 to $120 \mathrm{kN}$ (-6\%). Multiplying $k_{\mathrm{n}}$ by a factor of two the ultimate force of the joint, given by an offset of the linear stretch by $2 \%$, increases from 127.2 to $135.0 \mathrm{kN}(+7 \%)$.

The reduction/increase of the normal stiffness of the interface also affects the global stiffness of the joint; the global stiffness of the joint decreases as the normal stiffness of the interface decreases, being more sensitive to this variation when compared with the ultimate force. The reduction of $50 \%$ of the $k_{\mathrm{n}}$ parameter, results in a decrease of the slope of the first part of the response, from 32 to $26 \mathrm{kN} / \mathrm{mm}(-23 \%)$. On the other hand, the multiplication by a factor of 2 of this parameter results in an increase of the slope of the first part of the response, from 32 to $41 \mathrm{kN} / \mathrm{mm}(+28 \%)$.

Figure $14 \mathrm{~b}$ shows a comparison between the results of the variation of the $k_{\mathrm{s}}$ parameter. The ultimate force
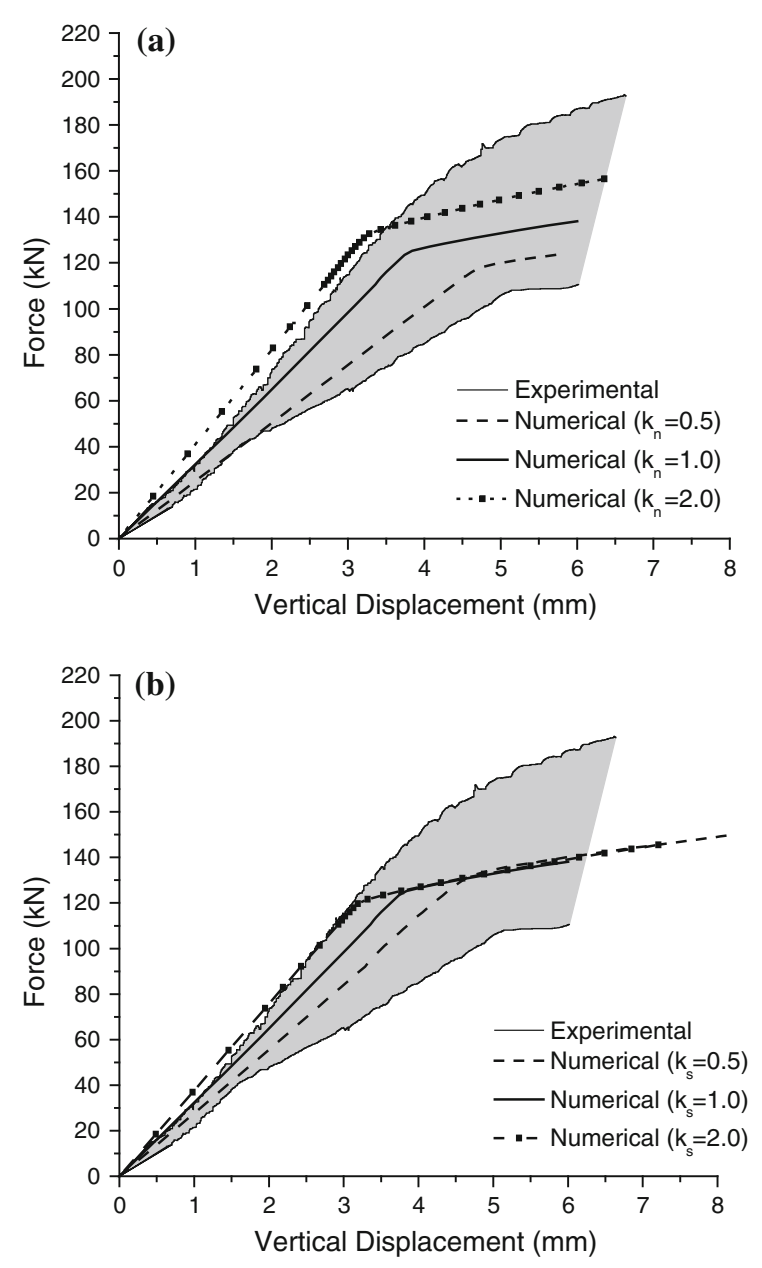

Fig. 14 Effect of the variation of parameter: $\mathbf{a} k_{\mathrm{n}}$, and $\mathbf{b} k_{\mathrm{s}}$ on the model response

is insensitive to a $k_{\mathrm{s}}$ variation, whereas the reduction/ increase of the $k_{\mathrm{s}}$ parameter affects the global stiffness of the joint: the global stiffness of the joint decreases as the $k_{\mathrm{s}}$ parameter decreases. The reduction of $50 \%$ of the $k_{\mathrm{s}}$ parameter, results in a decrease of the slope of the first part of the response, from 32 to $28 \mathrm{kN} / \mathrm{mm}$ ($14 \%)$. On the other hand, the multiplication by a factor of 2 of this parameter results in an increase of the slope of the first part of the response, from 32 to $37 \mathrm{kN} / \mathrm{mm}(+16 \%)$.

\subsubsection{Elastic modulus}

The effect of the variation of the modulus of elasticity parallel and perpendicular to the grain was considered individually, see [11] for details. Figure 15 indicates 

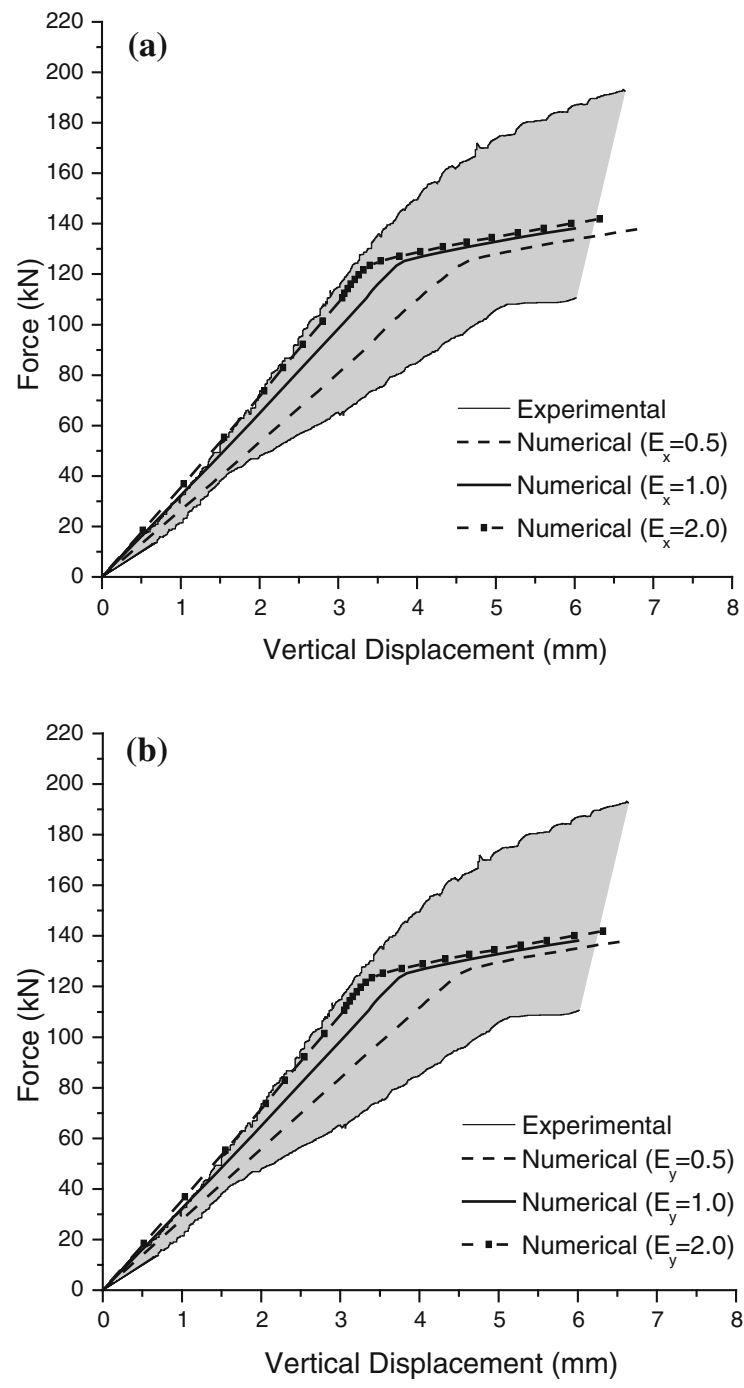

Fig. 15 Effect of the variation of the elastic modulus of elasticity on the model response $\mathbf{a} E_{x}$, and $\mathbf{b} E_{y}$

that the ultimate force is almost insensitive to the variation of the elastic modulus for wood $( \pm 4 \%)$, in both considered directions. The inclusion of the effects of the elastic modulus does change significantly the elastic stiffness of the joint. The reduction of $50 \%$ of the $E_{x}$ parameter, see Fig. 15a, results in a decrease of the slope of the first part of the response, from 32 to $28 \mathrm{kN} / \mathrm{mm}(-14 \%)$. On the other hand, the multiplication by a factor of 2 of this parameter results in an increase of the slope of the first part of the response, from 32 to $36 \mathrm{kN} / \mathrm{mm}(+13 \%)$.

The reduction of $50 \%$ of the $E_{y}$ parameter, see Fig. 15b, results in a decrease of the slope of the first
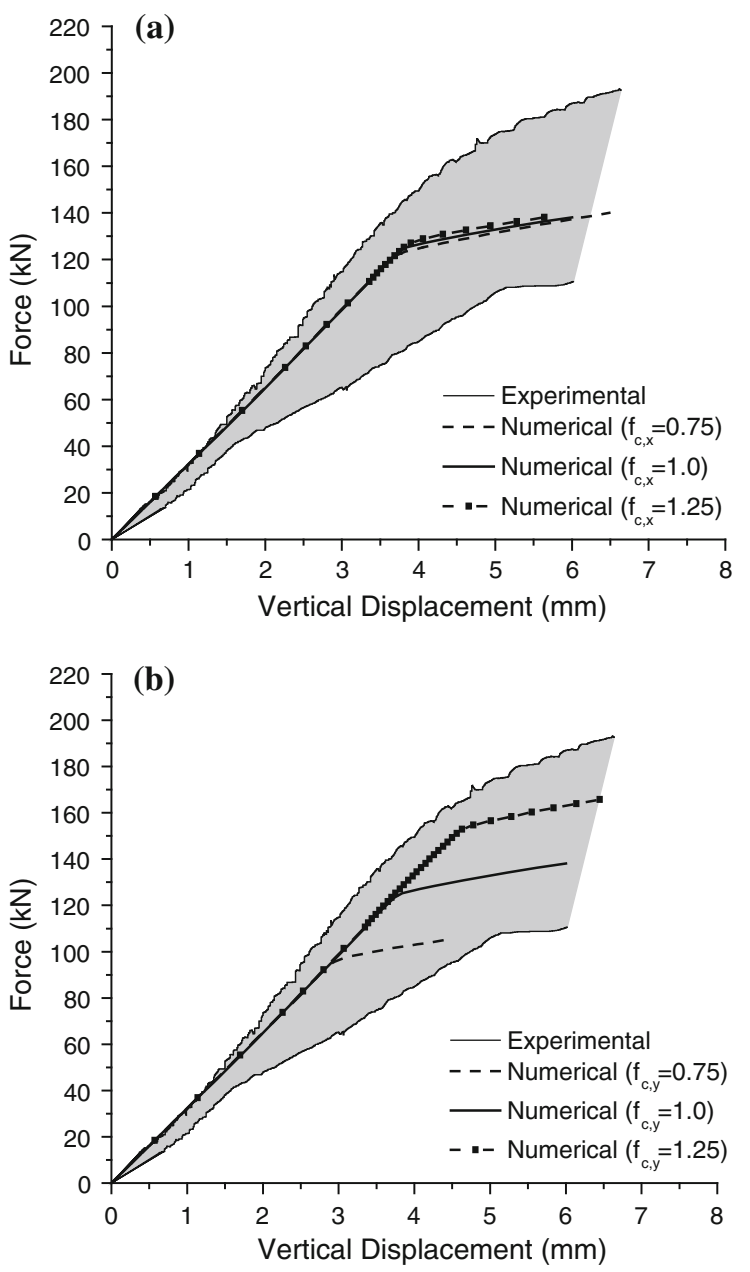

Fig. 16 Effect of the variation of the compressive strength on the model response $\mathbf{a} f_{\mathrm{c}, x}$, and $\mathbf{b} f_{\mathrm{c}, y}$

part of the response, from 32 to $28 \mathrm{kN} / \mathrm{mm}(-14 \%)$. On the other hand, the multiplication by a factor of 2 of this parameter results in an increase of the slope of the first part of the response, from 32 to $36 \mathrm{kN} / \mathrm{mm}$ $(+13 \%)$.

\subsubsection{Compressive strength}

Finally, the relationship between the global behaviour of the joint and the compressive strength of wood in both considered directions is shown in Fig. 16. It is apparent in Fig. 16a that the ultimate force and the global stiffness of the joint are insensitive to the variation of the compressive strength of wood in the direction parallel to the grain. Figure $16 \mathrm{~b}$ indicates higher sensitivity of the ultimate force of the joint to 
the variation of the compressive strength of wood in direction perpendicular to the grain, as expected: with a reduction of 0,75 , the ultimate force of the joint, given by an offset of the linear stretch by $2 \%$, decreases from 130 to $100 \mathrm{kN}(-30 \%)$; multiplying by a factor of 1.25 the ultimate force of the joint, given by an offset of the linear stretch by $2 \%$, increases from 130 to $160 \mathrm{kN}(+23 \%)$. However, the global stiffness of the joint is insensitive to the variation of the compressive strength perpendicular to the grain.

\section{Conclusions}

Despite the wide use of mortise and tenon joints in existing timber structures scarce information is available for design and in situ assessment. The objective of the present study was to quantify the strength capacity of a wood-wood mortise and tenon joint by physical testing of full-scale specimens. In addition, the performance of different semi and non-destructive tests for assessing global joint strength was also evaluated. Finally, the adequacy of an anisotropic failure criterion to represents the behaviour of a traditional mortise and tenon joint was assessed from the comparison between experimental and numerical results.

Two different wood groups have been used, one from new logs and another one from old logs (date, precise origin and load history unknown). Reducing the defects to a minimum, no influence could be attributed to service time. Thus, safety assessment of new timber structures, made from old or new wood elements, can be made using similar mechanical data.

Density, Resistograph and Pilodyn are recommended for qualitative assessment of timber elements. On the contrary, ultrasonic testing provided reasonable correlations for the joint strength. The results also show that the ultrasonic pulse velocity through the joint provides a reasonable estimate for the joint stiffness, or effectiveness of the assembly between the rafter and brace. Additionally, novel linear regressions have been proposed for chestnut mortise and tenon joints with interlocking.

The failure mechanism and load-displacement diagrams observed in the experiments are well captured by the used non-linear finite element analysis. Nevertheless, the normal stiffness of the interface has considerable influence in the yield strength and deformation of timber joints. The parameters that affect mostly the ultimate load of the timber joint are the compressive strength of wood perpendicular to the grain and the normal stiffness of the interface elements representing the contact between rafter and brace. The tangential stiffness of the interface and the Young's moduli of wood have only very limited influence in the response. The compressive strength of wood parallel to the grain has no influence in the response.

The sensitivity of ultimate force and stiffness of the joint towards the compression perpendicular to the grain and the modulus of elasticity, respectively, shows that SDT and NDT methods can provide some in situ information about the structural behavior of traditional timber mortise and tenon joints. This statement is based on: the correlation between ultrasonic velocity and ultimate load and stiffness found in the present study; and, the correlations found between the dynamic modulus of elasticity (ultrasonic) and the modulus of elasticity perpendicular to the grain determined by Lourenço et al. [19]. This information can be used to sustain a reliability analysis following the work performed for other types of timber joints [16].

The correlation found between ultrasonic tests and joint performance can be important and represent a step towards design/diagnosis, structural analysis and possible remedial measures of chestnut timber structures. Also, in the design of new timber structures and rehabilitation projects this correlation can be useful. However, without further experimental investigations, namely in others timber joint types, this correlation should be used as a comparative term, namely of the effectiveness of the joint, when analyzed in terms of a specific structure. Future research should therefore concentrate on the confirmation of this finding.

\section{References}

1. Aman R, West H, Cormier D (2008) An evaluation of loose tenon joint strength. For Prod J 58(3):61-64

2. Biechele T, Chui Y, Gong M (2010) Assessing stiffness on finger-jointed timber with different non-destructive testing techniques. In: Proceedings of the final conference of COST action E53

3. Bouchoir A, Vergne A (1995) An application of the Tsai criterion as a plastic-flow law for timber bolted joint modeling. Wood Sci Technol 30(1):3-19

4. Branco J (2008) Influence of the joints stiffness in the monotonic and cyclic behaviour of traditional timber 
trusses. Assessment of the efficacy of different strengthening techniques. $\mathrm{PhD}$ thesis, University of Minho and University of Trento

5. Branco J, Piazza M, Cruz PJS (2011) Experimental evaluation of different strengthening techniques of traditional timber connections. Eng Struct 33(8):2259-2270

6. CEN (1991) EN 26891 - Timber structures. Joints made with mechanical fasteners general principles for the determination of strength and deformation characteristics. European Committee for Standardization, Brussels, Belgium

7. CEN (2003) EN 408 - Timber structures. Structural timber and glued laminated timber. Determination of some physical and mechanical properties. European Committee for Standardization, Brussels, Belgium

8. Chen C, Lee T, Jeng D (2003) Finite element modeling for the mechanical behavior of dowel-type timber joints. Comput Struct 81(30-31):2731-2738

9. Eckelman C, Akcay H, Haviarova E (2007) Exploratory study of truss heel joints constructed with round mortise and tenon joints. For Prod J 57(9):68-72

10. Eckelman C, Haviarova E (2008) Rectangular mortise and tenon semirigid joint connection factors. For Prod $\mathbf{J}$ 58(12):49-55

11. Feio A (2006) Inspection and diagnosis of historical timber structures: NDT correlations and structural behaviour, $\mathrm{PhD}$ Thesis, University of Minho, Portugal. Available from www.civil.uminho.pt/masonry

12. Guan ZW, Rodd PD (2000) A three-dimensional finite element model for locally reinforced timber joints made with hollow dowel fasteners, Canadian. J Civil Eng 27(4):785-797

13. Haviarova E, Eckelman C (2009) Semi-rigid connection factors for small round mortise and tenon joints. For Prod J 59(9):55-60

14. Judd J, Fonseca F, Walker C, Thorley P (2012) Tensile strength of varied-angle mortise and tenon connections in timber frames. J Struct Eng 137(5):636-644

15. Kasal B, Tannert T (2010) In situ assessment of structural timber. RILEM state of the art reports

16. Leijten A, Köhler J, Jorissen A (2004) Review of probability data for timber connections with dowel-type fasteners. In: Proceedings of the 37 th meeting, international council for research and innovation in building and construction, working commission W18 - Timber structures, CIB-W18, Paper No. 37-7-13, Edinburgh, UK

17. Likos E, Haviarova E, Eckelman C, Erdil Y, Ozcifci A (2012) Effect of tenon geometry, grain orientation, and shoulder on bending moment capacity and moment rotation characteristics of mortise and tenon joints. Wood Fiber Sci 44(4):1-8

18. Lourenço P, De Borst R, Rots J (1997) A plane stress softening plasticity model for orthotropic materials. Int $\mathbf{J}$ Numer Methods Eng 40:4033-4057
19. Lourenço PB, Feio AO, Machado JS (2007) Chestnut wood in compression perpendicular to the grain: non-destructive correlations for test results in new and old wood. Constr Build Mater 21(8):1617-1627

20. Min K, Na Y, Qun C (2011) Studies on static performance of mortise and tenon joint in traditional column and tie construction timber structure. In: International conference on electric technology and civil engineering (ICETCE), pp 6197-6200

21. Moses D, Prion H (2003) A three-dimensional model for bolted connections in wood. Can J Civ Eng 30(3):555-567

22. Palma P, Cruz H (2007) Mechanical behaviour of traditional timber carpentry joints in service conditions - results of monotonic tests. In: From material to Structure - Mechanical behaviour and failures of the timber structures XVI international symposium, Venice, Italy. ICOMOS IWC

23. Parisi M, Piazza M (2000) Mechanics of plain and retrofitted traditional timber connections. J Struct Eng 126(12):1395-1403

24. Parisi M, Piazza M (2002) Seismic behavior and retrofitting of joints in traditional timber roof structures. Soil Dyn Earthq Eng 22(9-12):1183-1191

25. Ross R, Brashaw B, Pellerin R (1998) Nondestructive evaluation of wood. For Prod J 48(1):101-105

26. Sandberg LB, Bulleit WM, Reid EH (2000) Strength and stiffness of oak pegs in traditional timber-frame joints, J. Struct Eng ASCE 126(6):717-723

27. Saporiti J, Palma P (2011) Non-destructive evaluation of the bending behaviour of in-service pine timber structural elements. Mater Struct 44(5):901-910

28. Sawata K, Yasumura M (2003) Estimation of yield and ultimate strengths of bolted timber joints by nonlinear analysis and yield theory. J Wood Sci 49(5):83-391

29. Schmidt RJ, MacKay RB, Leu BL (1996) Design of joints in traditional timber frame buildings. In: Proceedings of the international wood engineering conference, New Orleans, LA, 28-31, vol 4, pp 240-247. Reprinted in-Timber frame joinery and design workbook, timber framers guild of North America, pp. 77-91

30. Schmidt R, Scholl G (2000) Load duration and seasoning effects on mortise and tenon connections. Research Report, University of Wyoming, Department of Civil and Architectural Engineering, Wyoming

31. Shanks J, Walker P (2009) Strength and stiffness of alltimber pegged connections. J Mater Civ Eng 21(1):10-18

32. Stehn L, Borjes K (2004) The influence of nail ductility on the load capacity of a glulam truss structure. Eng Struct 26(6):809-816

33. Villar JR, Guaita M, Vidal P, Arriaga F (2007) Analysis of the stress state at the cogging joint in timber structures. Biosyst Eng 96(1):79-90 